\title{
Sump bay fever: inhalational fever associated with a biologically contaminated water aerosol
}

\author{
Kenneth Anderson, Charles P McSharry, Colin Clark, Christopher J Clark, \\ G Robin Barclay, George P Morris
}

\begin{abstract}
Objective-To investigate the clinical, serological, and environmental features of a work related inhalational fever associated with exposure to an aerosol generated from a biologically contaminated 130000 gallon water pool in a building used for testing scientific equipment.

Method-Cross sectional survey of all exposed subjects $(n=83)$ by symptom questionnaire, clinical examination, spirometry, and serology for antibody to Pseudomonads, pool water extract, and endotoxin. In symptomatic patients diffusion capacity was measured, and chest radiology was performed if this was abnormal. Serial peak flow was recorded in those subjects with wheeze. Bacterial and fungal air sampling was performed before and during operation of the water pool pump mechanism. Endotoxin was measured in the trapped waters and in the pumps. Serum cotinine was measured as an objective indicator of smoking.
\end{abstract}

Results-Of the 20 symptomatic subjects, fever was most common in those with the highest exposure $\left(\chi^{2} 42 \cdot 7, P<0.001\right)$ in the sump bay when the water was (torrentially) recirculated by the water pumps. Symptoms occurred late in the working day only on days when the water pumps were used, and were independent of the serum cotinine. Pulmonary function was normal in most subjects (spirometry was normal in 79/83, diffusion capacity was low in five subjects, chest radiology was normal). Peak flow recording did not suggest a work relation. The bacterial content of the aerosol rose from 6 to $>10000$ colony forming units per cubic metre (cfu/m $\mathrm{m}^{3}$ ) (predominantly environmental Pseudomonads) when the pumps were operating. High endotoxin concentrations were measured in the waters and oil sumps in the pumps. Low concentrations of antibody to the organisms isolated were detected (apart from two subjects with high antibody) but there was no relation to exposure or the presence of symptoms and similar antibody was found in the serum samples from a nonexposed population. The fever symptoms settled completely with the simple expedient of changing the water and cleaning the pumps.

Conclusion-Given the results of our study, the development of inhalational fever in this unique environment and clearly restricted cohort was closely related to the degree of exposure to contaminated aerosol and mainly occurred in the absence of distinct serological abnormality and independent of cigarette smoking.

(Occup Environ Med 1996;53:106-111)

Keywords: inhalational fever; biological aerosol; extrinsic allergic alveolitis

The development of fever after exposure to aerosol is a consistent observation in varying circumstances and has been included in the descriptive title of a group of pulmonary disorders caused by diverse industrial processes or contaminated environments. Whether the exposure is to grain dust, ${ }^{1}$ cotton and fibre processing, ${ }^{2}$ metal fumes, ${ }^{3}$ polymer fumes, ${ }^{4}$ biologically contaminated humidifiers, ${ }^{5}$ fungal spores, ${ }^{6}$ or lake water, ${ }^{7}$ fever is often the most obvious complaint, but the precise pathogenesis of this fever is uncertain.

As shortness of breath or pulmonary involvement by radiology or physiology were less obvious than fever the diagnosis of extrinsic allergic alveolitis in these cases seems unlikely, although the other associated symptoms of systemic disturbance (muscle ache, headache, tiredness, anorexia, shivering, and chills) in both illness groups can be very similar. So it is a reasonable general assumption that the fever illnesses and extrinsic allergic alveolitis may overlap aetiologically. This hypothesis is supported by reports of outbreaks of both disorders, usually in an enclosed environment, where both extrinsic allergic alveolitis and fever occurred simultaneously after exposure to what was assumed to be a similar aerosol. ${ }^{89}$

We describe a cross sectional study of an outbreak of fever which developed in some of the employees who worked in an enclosed building uniquely designed to serve a large water pool and related scientific testing equipment. Our particular aim was to examine exposure relations and to determine whether serological variables were of any relevance.

Materials and methods

WORKER ASSESSMENT

All staff ( $n=83$ ) who worked in an interconnecting complex of buildings completed a screening questionnaire (which had been used previously in an outbreak investigation elsewhere $^{8}$ ) about sex, age, work history, 
predominant workplace, and duration of time spent in the suspect area known as the sump bay. Presence or absence and duration of chest symptoms (cough, shortness of breath, chest tightness, wheeze, haemoptysis) or systemic symptoms (fever, sweating, weight loss, anorexia, lassitude, headache, skin irritation, or eczema) over the previous six months was noted, as well as a record of health and smoking history.

On the three days after a burst of work force symptoms, all of the employees completed the questionnaire and were interviewed by a doctor (KA). The precise timing and severity of the reported symptoms were clarified as closely as possible, as were the exposure details and work history, and the subject's perception of the cause was discussed. A physical examination was performed, then the forced expiratory volume in one second $\left(\mathrm{FEV}_{1}\right)$ and forced vital capacity (FVC) were recorded with a wedge spirometer which was calibrated on site.

Venous blood was collected into EDTA and plain bottles. A total white blood count was measured on a Coulter Counter CBC (Coulter Electronics) and a differential count was measured on blood films with an 800 cell count. Serum samples were separated from the clotted sample by centrifugation and stored at $-20^{\circ} \mathrm{C}$ until use.

Depending on the history, diffusion capacity was measured at a local hospital, and if this was abnormal, then a chest radiograph was also taken. A single transbronchial biopsy was performed in one person who also underwent bronchoalveolar lavage.

Five subjects with wheeze completed twohourly peak flow recordings with a mini Wright peak flow meter over a four week period. Table 1 shows the number of patients who underwent each test.

DESCRIPTION OF THE BUILDING

The main part of the building, which was built in 1972, was a large open area about $50 \mathrm{~m}$ long, $30 \mathrm{~m}$ wide, and three stories high (the sump bay). There was a two floor basement which housed a 130000 gallon water tank and valve mechanism. This was connected by a weir to another tank (the dump sump) at a lower level which also drained water from around the walls of the building and was emptied intermittently, depending on the water level in the tank, to a large pond outside. During operation of two surface mounted high power pump motors (where the controlling engineers mainly stood) water from the main tank was diverted to tanks at the roof level and then, through a system of valves and pipes to test scientific and engineering equipment. The surface of the main tank was covered by close fitting metal plates which could be removed by a crane for service access. The lower level tank was reached through manually raised, loose hinged, metal covers close to the large pumps.

The sump bay was connected to two groups of offices-one close to and the other further away from the sump bay. All parts of the building were naturally ventilated and there was no history of water ingress or recent construction.
The water in the main tank was routinely changed, annually in July, and during the changeover the walls of the tanks were cleaned by high pressure water jets to remove sediment. The water was treated with a bromine based commercial biocide which was put into the water monthly.

ENVIRONMENTAL SAMPLING

Water was taken for bacterial culture and measurement of endotoxin from the main tank, drain tank (dump sump), local drinking water, and drinking water elsewhere.

Fluids (oil and water mixtures) were aspirated by syringe from various tubes and drainpans around the surface pumps for culture and for measurement of endotoxin. The endotoxin content of these samples was measured by a kinetic chromogenic limulus amoebocyte lysate (LAL) test with the Chromogenix COATEST endotoxin kit. Results were expressed in relation to the kit endotoxin standard in endotoxin units $(E U) / m l$. Samples were tested at neat, 1:10, and 1:100 dilutions in pyrogen free water, and results were taken from the ones which lay on the standard curve (extrapolated values were not used). To test the oily samples, $1 \mathrm{ml}$ of sample was mixed with $1 \mathrm{ml}$ of pyrogen free water and mixed (roller mixer) for one hour. To test the containers, $1 \mathrm{ml}$ of pyrogen free water was added to a container and left on a roller mixer for one hour.

Endotoxin core antibody (EndoCAb) ${ }^{10}$ is assayed with a cocktail of rough lipopolysaccharide (R-LPS) from four common Gram negative species, Escherishia coli, Salmonella, Klebsiella, and Pseudomonas. The R-LPSs contain no O-specific (serotypic chains) and are size selected not to express the outer LPS core, so only antibodies to the inner LPS core (lipid-A, HEP, Kdo region) are detected. As four species of LPS are used, only antibodies which are cross reactive can give maximal reactivity in this enzyme linked immunosorbent assay (ELISA) by binding to all antigens. The results were compared with normal adult ranges for immunoglobulin G (IgG), IgM, and IgA EndoCAb, with the 10th and 90th percentiles of these ranges as markers of low and high levels. The units of EndoCAb are median units (MU) taken as $100 \%$ of the median of each ( $G, M$, or A) normal range (hence the median of each range equals $100 \mathrm{MU}$ ). Legionella serology was performed by indirect fluorescence.

ANTIGEN PREPARATIONS USED FOR SEROLOGY The sump water was collected and concentrated 100-fold (Amicon minicon cells). This was dialysed against $0.02 \mathrm{M}$ carbonate buffer $\mathrm{pH} 9.6$ overnight at $4^{\circ} \mathrm{C}$ and stored frozen until use. Overnight broth cultures of Pseudomonas testeroni, Pseudomonas putrefaciens, and Pseudomonas aeruginosa cultured from the sump were centrifuged to pellet the organisms. These were washed twice with saline and an antigenic extract was prepared by sonication (Branson sonifier 250, Dawe

\section{Electronics, Middlesex).}

Table 1 Number of each test

\begin{tabular}{lc}
\hline Investigation & $n$ \\
\hline Symptom questionnaire & 83 \\
Examination & 83 \\
Venesection & 79 \\
Spirometry & 83 \\
Diffusion capacity & 20 \\
Radiology & 5 \\
Peak flow record & 5 \\
\hline
\end{tabular}


Airborne samples were taken with a surface air sampler (Cherwell Laboratories, England) with appropriate media for bacterial and fungal isolation. The samples were obtained at various sites throughout the complex of offices, in the testing areas, and around the surface pumps before and during their operation.

\section{IgE AND IgE ANTIBODIES}

Total serum IgE and IgE antibodies to house dust mite (d1) and grass pollen (g8) were measured with Phadebas RAST kits (Pharmacia UK) according to the manufacturer's recommendations. Total IgE was measured in international units $/ \mathrm{ml}$ (IU $/ \mathrm{ml}$ ), and IgE antibody titres were measured in arbitrary RAST units $/ \mathrm{ml}(\mathrm{U} / \mathrm{ml})$; concentrations $>0.35 \mathrm{U} / \mathrm{ml}$ were considered to be significant. The quality control of this assay was continually assessed by the satisfactory performance of daily internal control samples and monthly national control samples. An estimate of the measurement error was made at $20 \%$ based on the coefficient of variation of the measurements of the same internal quality control samples over 50 consecutive weeks.

Atopy was defined for the purposes of this report as seropositivity to at least one of the common allergens, house dust mite or grass pollen.

\section{IgG AND IgG ANTIBODY}

Total serum IgG was measured by nephelometry (Behring) and IgG antibody to antigens was identified by immunoprecipitation (Oucterlony gel precipitation) and measured by an enzyme immunoassay (EIA). Optimal proportions of the reagents for the EIA, established by checkerboard titration, were: antigen solution at $10 \mu \mathrm{g} / \mathrm{ml}$, control and test serum samples diluted 1 in 50, and alkaline phosphatase conjugated antihuman IgG or IgM, diluted 1 in 1000 (isotype specific, monoclonal antihuman IgG or IgM, Sigma, UK). The EIA method was measured with 30 normal control serum samples from healthy laboratory personnel and four known antibody positive control serum samples from patients with cystic fibrosis. The normal control serum samples generated a value for the upper limit of normal (ULN) which was the mean plus 2 SDs of the absorbance at $405 \mathrm{~nm}$ $\left(\mathrm{A}_{405}\right)$. One of the strongly positive serum samples was assigned an arbitrary value of 100 $\mathrm{U} / \mathrm{ml}$ and a specific binding index (SBI) in $\mathrm{U} / \mathrm{ml}$ for each test serum sample, relative to the controls, was defined as the quotient of:

$\left(\mathrm{A}_{405}\right.$ test serum $\left.-\mathrm{A}_{405} \mathrm{ULN}\right) \times 100$ and

$\left(A_{405} 100 \mathrm{U}\right.$ positive serum sample $\left.-A_{405} U L N\right)$.

This index was chosen so that a value of zero represents the upper limit of normality and any value greater than this was regarded as significant. The coefficients of variation for within and between assay measurements were $8.9 \%$ and $13.4 \%$, respectively. The specificity of the assay was shown by specific inhibition of the antibody activity in a moderate titre serum sample by equilibrating with free antigen.
COTININE AND CIGARETTE SMOKING

Serum cotinine concentrations were measured by adapting a radioimmunoassay kit used for urinary cotinine estimation (EURO/DPC, Llanberis); non-smokers generally have concentrations $<15 \mathrm{ng} / \mathrm{ml} .^{11}$

\section{STATISTICAL ANALYSIS}

The significance of the differences between sample means was assessed by the MannWhitney U test. Correlations between categorical variables was assessed by the $\chi^{2}$ test.

\section{Results}

All 83 workers from the building completed the questionnaire and attended the interview for history, examination, and spirometry. Four subjects (three women, and one man) did not consent to blood sampling.

\section{SYMPTOM ANALYSIS}

Work related symptoms were recorded by 20 people (19 men). The most common symptom was fever which developed in 17 people as well as various associated systemic complaintsheadache (10), tiredness (13), muscle or joint pain (12) chest tightness or discomfort (7), nausea (12), diaphoresis (8), gastrointestinal upset (2), cough (5), wheeze (3), shortness of breath (mild in 5, more marked in 1). Three other people had similar symptoms without fever.

These symptoms developed late in the afternoon or in the evening at home only on the days when the sump bay machinery was in operation. The first recorded episode occurred in November 1992 which was four months after the annual service and water change. Several subsequent episodes of symptoms in the staff who were in attendance occurred on various weekdays clearly associated with the function of the sump bay.

Symptoms without recollection of a clear relation to work were recorded by 29 people. In these workers, the symptoms (fever 13, headache 15, throat discomfort 15 , muscle pain or joint ache 11 , cough 17 , diaphoresis 8 , nasal discharge 18 , wheeze 2 , and weight loss 1) were more prolonged and less episodic. Most of these subjects attributed the symptoms to a single episode of winter viral infection, but 13 of these subjects were less certain of the cause, duration of the symptoms, or their own work pattern at the time when the symptoms developed and were classified for the purpose of the study as suspicious. One subject lost weight and had diaphoresis and fever which developed during the period of study and was diagnosed as thyrotoxic.

All the staff within the building had passed through the sump bay area at some time since the annual service and during the symptomatic spell. As the health problem in some of the workers was recognised to be within this part of the building there was a tendency for the staff to avoid the area if possible. Based on time spent in the sump bay, there were three distinct groups-those who worked in the offices and rarely walked through (negligible 
Table 2 Demographic data and work details with symptom profile during the previous four months

\begin{tabular}{llll}
\hline & \multicolumn{2}{l}{ Estimated exposure } & \\
\cline { 2 - 4 } & $\begin{array}{l}\text { Close } \\
(n=21,0 \text { women })\end{array}$ & $\begin{array}{l}\text { Occasional } \\
(n=49,3 \text { women })\end{array}$ & $\begin{array}{l}\text { Negligible } \\
(n=13,9 \text { women })\end{array}$ \\
\hline Age (median (range)) & $44(19-58)$ & $37(18-64)$ & $30(22-53)$ \\
Service (median (range), y) & $17(1-20)$ & $12(0 \cdot 5-20)$ & $8(0 \cdot 5-20)$ \\
Fever (n) & 16 & 4 & 0 \\
Suspicious (n) & 4 & 9 & $0 \dagger$ \\
Airway (n) & 3 & 12 & $3 \ddagger$ \\
Other (n) & 2 & 20 & $7^{\star \star \star}$ \\
Smokers (n) & 11 & 9 & 1 \\
No feverish symptoms (n) & 0 & 24 & $11^{\star \star \star}$ \\
\hline
\end{tabular}

$\star \star P<0.01 ; \star \star \star P<0.001 ; \dagger P=0.058 ; \ddagger P=0.634$

Fever $=$ all subjects who reported two or more episodes of pyrexia and systemic symptoms with a clear work relation during the previous four months; suspicious $=$ those subjects with only one episode of fever but recurrent systemic symptoms with a clear work relation; airway $=$ those subjects in whom the main symptoms reported were cough or wheeze; other = those subjects with symptoms which were clearly not work related.

exposure), those who had offices nearby who were predominantly involved in scientific testing (occasional exposure), and those who worked more continuously in the sump bay and were responsible for the heavy machinery and engineering aspects of the tests (close exposure). Table 2 shows the symptom profile for these groups according to the work practice (and history of cigarette smoking ).

PULMONARY FUNCTION AND RADIOLOGY

Spirometry was within the normal predicted range in 79 of 83 . Mild air flow obstruction was present in three subjects $(<15 \%$ reduction from predicted $\mathrm{FEV}_{1}$ ) and considerable obstruction ( $45 \%$ reduction) was present in one subject. All four had work related fever. Diffusion capacity was measured in 20 subjects and was normal in 15-a reduction was noted in five subjects, range $12 \%-16 \%$. The test was repeated in the five subjects in whom the results were abnormal (the most symptomatic subjects) one week after removal from work in the sump bay. An improvement in their results was noted (approaching 10\%).

Diary card peak flow recording two-hourly over four weeks in five subjects who had recorded wheeze on the symptom questionnaire did not suggest a work relation.

Chest radiology was normal in the five most symptomatic subjects. High resolution computed tomography of the thorax in one subject was normal.

\section{ENVIRONMENTAL SAMPLING}

Water was removed from the main tank, the drain tank (dump sump), and from the area around the main pumps (free standing, $2 \mathrm{~m}$ high, with a central spinning axle visible through metal grills at waist and head height) where there were several blind ending drains and overflow pipes. These pipes were difficult to sample but fluid could be aspirated with syringes, narrow gauge plastic tubing, and a three way tap.

About three litres of discoloured oil and water mixture was found inside a casing of one of the pumps which was obscured by a protective plate in a "dead" area of the pump. As the central axle spinned, an aerosol was generated which passed through the metal grills creating a slightly acrid mist in the area around the pumps and the dump sump where the engi- neers (particularly the foreman, who had the most debilitating illness) would be positioned during the test periods. The smell was not detected during every test and some people could not sense any change in air quality at any time.

Environmental pseudomonads were easily cultured in all the waters and fluids from the pumps, main tank, and dump sump (Pseudomonas putrifaciens, Pseudomonas testeroni, and Alcaligenes species). Air sampling over the main tank produced eight colony forming units per cubic metre $\left(\mathrm{cfu} / \mathrm{m}^{3}\right)$ when the water was undisturbed and more than $10000 \mathrm{cfu} / \mathrm{m}^{3}$ when the water was turbulent. Table 3 shows the fluid concentrations of endotoxin for the various sites. The air sample isolates for fungi produced $50-100 \mathrm{cfu} / \mathrm{m}^{3}$ (predominantly Penicillium species).

\section{WHITE CELL COUNTS AND SEROLOGY}

The total white cell count was normal in 79 of 83 (median 8800 cells $/ \mathrm{m}^{3}$, interquartile range 7900-10 200). Three subjects had mild leukocytosis of 1420, 1440, and 1650, and were spread equally among the exposure groups. Differential white counts were all normal. Total IgG concentrations were normal (median $10 \cdot 5$, interquartile range $9 \cdot 5-11 \cdot 5$ ). The IgE antibody to house dust mite or grass pollen was present in 30/85 (32\%). Total IgE (median $33 \mathrm{U} / \mathrm{ml}$, interquartile range 16-135) concentrations were normal.

Precipitins to water antigen were found in one subject. Enzyme immunoassay detected specific IgG antibody to water antigen in two subjects and IgM antibody in four others. No significant titres greater than normal were found to the pseudomonads isolated from the water. The endotoxin core antibody antigen responses were within normal limits.

All serum samples tested negative for Legionella antibodies.

Serum cotinine clearly distinguished the smokers ( $n=20$, median 330, interquartile range $72 \cdot 5-540)$ from the non-smokers $(n=$ 63 , median 19, interquartile range 10-30): $\mathrm{P}<0.001$.

When analysed in terms of exposure or disease category there were no significant differences in serological or white blood cell findings (table 4).

\section{RESOLUTION}

The water in the main tank was drained, replaced, and chlorinated. The pump machinery was cleaned and any redundant tubing was removed. Ventilation to the building was increased during operational testing by par-

Table 4 Median haematological results

\begin{tabular}{lccc}
\hline & \multicolumn{3}{c}{ Estimated exposure } \\
\cline { 2 - 4 } & Close & Occasional & Negligible \\
\hline Total white cells & $9 \cdot 7$ & $8 \cdot 5$ & $9 \cdot 7$ \\
Total IgG (mg/ml) & $10 \cdot 7$ & $10 \cdot 4$ & $10 \cdot 04$ \\
Total IgE (IU/ml) & 66 & $37 \cdot 5$ & 45 \\
House dust mite IgE & $0 \cdot 4$ & $0 \cdot 4$ & $0 \cdot 35$ \\
Grass pollen IgE & $0 \cdot 3$ & $0 \cdot 3$ & $0 \cdot 3$ \\
IgG to Pseudomonas aeruginosa & 0 & 0 & 1 \\
IgG to Pseudomonas cepacia & 0 & 1 & 3 \\
\hline
\end{tabular}


tially opening large cantilever access doors which were adjacent to the pump area. Symptoms have now entirely gone except in the foreman who was likely to have experienced the highest exposures. In his case, significant air flow obstruction persists and he has not returned to his original workplace. Bacteria are still present in the main tank but so far the overall count of organisms is much lower.

\section{Discussion}

The investigative approach to an outbreak of respiratory illness where there is likely to be a significant water related aetiological factor is complex in view of the wide spectrum of possible diseases and the responsible agents. ${ }^{12}$ Where there is a prominent complaint of recurrent fever among the affected population, the disorder is more likely to be of a non-infectious nature and the balance of approach is in favour of extrinsic allergic alveolitis or an inhalational fever syndrome. Water was likely to be a major factor in this report given the procedures of the workplace. The structure of the buildings and the neatly divided exposures of the workers offered an opportunity to examine more closely the development of symptoms and serology.

Cross sectional studies of this type have the inherent difficulty that the circumstances associated with the perception of symptoms are dynamic. The workers had already begun to avoid the sump bay when the study was performed so it may be that our data have been diluted by a degree of recovery (an interlude of about five days had elapsed since the last outbreak of symptoms). Nevertheless, we were able to show a strong relation between work related fever symptoms and exposure on the basis of time spent within the sump bay.

Although precipitins against antigens in the water were detected in one subject, the serology of the illness was largely unhelpful. Despite reasonably thorough investigation we were unable to detect any relation between exposure and the development of a significant antibody response against water antigens, organisms isolated, or endotoxin. Our most highly exposed subjects also had the highest incidence of fever symptoms, and if allergic alveolitis is dose dependent then it might have been expected within this group. However, this group also had a high number of cigarette smokers and it may be that the immune response within the lung to these inhaled materials was attenuated so that neither an antibody response nor allergic alveolitis developed. ${ }^{13-15}$

Our study included all subjects in the building and was designed to investigate those who seemed to have more extensive symptoms with the assumption that the most symptomatic people would have the clearest findings. Ideally, everyone should have had more pulmonary physiology, perhaps including exercise and radiology as well as bronchoalveolar lavage. In retrospect, given that the time since the last exposure to aerosol and performance of extensive practical procedures was increas- ing, and the group was so large, we think that our approach was probably correct.

An alternative method of investigation is to perform a controlled exposure to the suspect aerosol. This has the disadvantage of uncertainty over the actual quantity and duration of exposure experienced in the workplace as well as activity of the subjects. Most of the symptomatic subjects were industrial workers who would intermittently assemble heavy engineering equipment but there were others who had a more sedentary observational role where the inhaled dose might have been quite different. Negotiating this problem is feasible by challenging previously non-exposed subjects (usually volunteers or animals) and this approach was adopted recently in the study of swine fever. ${ }^{16}$ The main concern about this type of exposure is that illness or subsequent hypersensitivity may be induced in an otherwise well person so the criteria for challenge must be rigorous, ethical, and scientifically sound. On this basis we do not think that aerosol challenge in our subjects would have given much more information than our investigative protocol, at least from the point of view of categorisation of disease.

The similarities between the symptoms in our subjects and those which are found in other similar syndromes already mentioned does suggest a similar aetiology. Recently a unifying descriptive title of inhalational fever was proposed in place of the sometimes more parochial names used previously. ${ }^{17}$ The newer title was partly justified on the basis of the apparent differences between inhalational fevers and extrinsic allergic alveolitis where more consistently abnormal measurements in lung physiology, radiology, bronchoalveolar lavage cells, serology, and incidence are detected. ${ }^{18}{ }^{19}$ Inhalational fever has very similar systemic symptoms but in comparison, has a high prevalence-20\% for sawmill workers ${ }^{19}$ and nearly $1 \%$ in farmers ${ }^{20}$-higher than the rates of allergic alveolitis in the same groups. The high prevalence of fever in our study in the most highly exposed subjects possibly reflects the consistent and recent nature of this exposure. Perhaps this is a unique group of subjects which comes very close to a field exposure group, although the results may be skewed by the presence of so many cigarette smokers in the workers who were judged to have experienced the highest exposure.

It is possible that the general method of gathering symptom reports (for instance, by questionnaire) will influence the subsequent calculation and underestimate disease prevalence as the characteristics of large groups, such as farmers, might have exposures which vary widely. Similarly, the higher prevalence in our study may also be an effect of close examination of an outbreak episode when the recollection of the patients might be more reliable. Also, reported symptoms can be carefully scrutinised during investigation of an outbreak because of the immediate access to the subjects. Alternatively, our prevalence may simply be high because the enclosed environment concentrated the contaminated aerosol. We 
thought that separation of our exposure groups was valid because of the clearly different habits of the staff within the building. If taken altogether, without categorising exposure, this would have produced a lower prevalence of $26 \%$. In other water related fever outbreaks in buildings (which may be the best studies for comparison), Ganier and colleagues recorded a prevalence of $52 \%$ for a North American outbreak of humidifier fever (or allergic alveolitis but no abnormal chest radiographs or pulmonary functions were detected). ${ }^{21}$ The printers' outbreak of humidifier fever reported by Parrot and Blyth recorded symptoms in $27 \%$ of those exposed. ${ }^{22}$ Overall, in Scotland, seven outbreaks of humidifier fever have been reported from five different buildings, and symptoms were identified in $10.3 \%$ of the 927 people exposed to the output of contaminated humidifiers, ${ }^{23}$ but only one case of allergic alveolitis related to a humidifier has been found ${ }^{8}$ - figures which are closer to some of the studies already mentioned. It is worth stating that the symptoms of humidifier fever (and presumably the other fever syndromes) are highly variable within groups of subjects-some do not consistently complain of fever and may only have a nonspecific complaint such as headache which can be timed along with the appearance of fever in others who are similarly exposed. ${ }^{24}$ Symptoms which are also presumably caused by the circulating cytokines arise as a consequence of inhalation of these aerosols. ${ }^{25}$

It is not known what determines the fever component as the principal mode of response or what induces allergic alveolitis, although the degree and duration of exposure may be relevant. Malmberg and colleagues considered that allergic alveolitis in farmers required repetitive exposure whereas inhalational fever seemed to be a consequence of sudden, heavy exposure, ${ }^{20} \mathrm{a}$ finding which they verified more recently by aerosol sampling. ${ }^{26}$ The apparent absence of allergic alveolitis in our study may therefore simply reflect the short and irregular nature of the exposures in our workforce. We have, however, shown that a clear work exposure relation with the development of inhalational fever is independent of a history of cigarette smoking and is also without any evidence of a related serological disturbance.

1 Pratt DS, May IJ. Feed associated respiratory illness in farmers. Arch Environ Health 1984;39:43-8.
2 Uragoda CG. An investigation into the health of kapok workers. $B r$ f Ind Med 1977;34:181-5.

3 Mueller E, Seger D. Metal fume fever: a review. 7 Emerg Med 1985;2:271-4.

4 Harris DK. Polymer fume fever. Lancet 1951;7814: 1008-11.

5 Anderson K, Watt AD, Sinclair D, Lewis C, McSharry C, Boyd G. Climate, intermittent humidification and humidifier fever. $\operatorname{Br} \mathcal{F}$ Ind Med 1989;46:671-4.

6 Rask-Andersen A. Organic toxic dust syndrome among farmers. BrF Ind Med 1989;46:233-8.

7 Muittari A, Kuusisto P, Virtanen P, Sovijarvi A, Glenroos $\mathrm{P}$, Harmoinen $\mathrm{A}$, et al. An epidemic of allergic alveolitis caused by tap water. Clin Allergy 1980;10:77-90.

8 Anderson K, McSharry C, Boyd G. Radiographic changes in humidifier fever. Thorax 1985;40:312-3.

9 Baur X, Behr J, Dewair M, Ehret W, Fruhmann G, Vogelmeier C, et al. Humidifier lung and humidifier fever. Lung 1988;166:113-24.

10 Barclay GR. Endogenous endotoxin-core antibody (EndoCAb) as a marker of endotoxin exposure and a prognostic indicator: a review. In: Levin J, Alving $C R$, Munford RS, Redl H, eds. Bacterial endotoxins: lipopolysaccharides from genes to therapy. New York: John Wiley, 1995:263-72.

11 McSharry C, Anderson K, McKay IC, Collof MJ, Feyeraband C, Wilson RB, et al. The IgE and IgG antibody responses to aerosols of Nephrops norvegicus (prawn) antigen: the association with clinical hypersensitivity and with cigarette smoking. Clin Exp Immunol 1994;97:499-504.

12 Rose CS. Water-related lung diseases. Occupational medicine: state of the art reviews. Philadelphia: Hanley and Belfus, 1992;7:271-86.

13 Warren CPW. Extrinsic allergic alveolitis: a disease commoner in non-smokers. Thorax 1977;32:567-9.

14 Anderson K, Morrison SM, Bourke SJ, Boyd G. The effect of cigarette smoking on the antibody response in pigeon breeders disease. Thorax 1988;43:798-800.

15 McSharry CP, Banham SW, Lynch PP, Boyd G. The effect of cigarette smoking on the antibody response and prevalence of extrinsic allergic alveolitis among pigeon breeders. Clin Allergy 1985;15:487-94.

16 Malmberg $\mathrm{P}$, Larsonn $\mathrm{K}$, Larsonn $\mathrm{PH}$, Isakson BM, Muller-Suu C. NK-cells increase in BAL-fluid after exposure to swine dust [abstract]. Am Rev Respir Dis 1994;140:A78.

17 Rask-Andersen A, Pratt DS. Inhalational fever: a proposed unifying term for febrile reactions of noxious substances. Br f Ind Med 1992;49:40.

18 Halpin DMG, Graneek BJ, Lacey J, Nieuwenhuijsen MJ, Williamson PAM, Venables KM, et al. Respiratory symptoms, immunological responses, and aeroallergen concentrations at a sawmill. Occup Environ Med 1994;51:165-72.

19 Rask-Andersen A, Land CJ, Enlund A. Inhalation fever and respiratory symptoms in the trimming department of Swedish sawmills. Am F Ind Med 1994;25:65-7.

20 Malmberg P, Rask-Andersen A, Hoglund S, KolmodinHedman B, Read-Guernsey J. Incidence of organic dust toxic syndrome and allergic alveolitis in Swedish farmers. toxic syndrome and allergic alveolitis in Swedish

21 Ganier M, Lieberman P, Fink J, Lockwood DG. Humidifier lung: an outbreak in office workers. Chest 1980;77:183-7.

22 Parrot WF, Blyth W. Another causal factor in the production of humidifier fever. Fournal of the Society of Occupational Medicine 1980;30:63-8.

23 Anderson K, McSharry CP, Boyd G. Humidifier fever in Scotland. Environmental Health Scotland 1989;3:10-1.

24 Anderson K. Factors influencing the development, investigation and resolution of humidifier-related diseases. Glasgow: tion and resolution of humidifier-related disease

25 Blanc PD, Boushey HA, Wong $H$, Wintermyer SF, Bernstein MS. Cytokines in metal fume fever. Am Rev Respir Dis 1993;147:134-8.

26 Malmberg P, Rask-Andersen A, Rosenhall L. Exposure to microorganisms associated with allergic alveolitis and febrile reactions to mold dust in farmers. Chest 1993; 103:1202-9. 